$\$$ Research Square

\title{
Placental abruption: assessing trends in risk factors over time
}

\section{Erga schur ( $\nabla$ erga.schur@gmail.com )}

Ben-Gurion University of the Negev https://orcid.org/0000-0003-2170-3808

\section{YAEL BAUMFELD}

Ben-Gurion University of the Negev

\section{REUT ROTEM}

Shaare Zedek Medical Center

\section{ADI Y. WEINTRAUB}

Ben-Gurion University of the Negev

\section{GALI PARIENTE}

Ben-Gurion University of the Negev

\section{Research Article}

Keywords: Placental abruption, Risk factors, Time trend analysis, Incidence

Posted Date: February 14th, 2022

DOI: https://doi.org/10.21203/rs.3.rs-1346837/v1

License: (c) (i) This work is licensed under a Creative Commons Attribution 4.0 International License. Read Full License 
Placental abruption: assessing trends in risk factors over time

ERGA SCHUR ${ }^{1}$, YAEL BAUMFELD MD ${ }^{1}$, REUT ROTEM MD MPH², ADI Y. WEINTRAUB MD ${ }^{1}$, GALI PARIENTE MD ${ }^{1}$

${ }^{1}$ Department of Obstetrics and Gynecology, Soroka University Medical Center, Faculty of Health Sciences, Ben-Gurion University of the Negev, Beer-Sheva, Israel

${ }^{2}$ Department of Obstetrics and Gynecology, Shaare Zedek Medical Center, Jerusalem, affiliated with the Hebrew University Medical School of Jerusalem

* In memory of Dr. David Yohay, a beloved physician and teacher who passed away while working on this study

\section{Corresponding author:}

\section{Erga Schur}

Department of Obstetrics and Gynecology

Soroka University Medical Center

POB 151

Beer-Sheva 84101, Israel

Celular: +972-507696089

Email: erga.schur@gmail.com 


\section{ABSTRACT}

Purpose: To evaluate changes in the independent contribution of different risk factors for placental abruption over time.

Methods: In this retrospective nested case control study, trends of change in ORs for known risk factors for placental abruption occurring in three consecutive eight-year intervals were compared. A univariate assessment of factors associated with placental abruption and two multivariable logistic regression models were constructed in order to identify independent risk factors for placental abruption. Trends of change in the incidence and specific contribution of various risk factors were compared along the study time period.

Results: During the study period 295,946 pregnancies met the inclusion criteria, of these, $2170(0.73 \%)$ were complicated with placental abruption. Using logistic regression models, previous cesarean delivery, in vitro fertilization (IVF) pregnancy, hypertensive disorders, polyhydramnios and inadequate prenatal care were recognized as independent risk factors for placental abruption. While the relative contribution of IVF pregnancy and polyhydramnios to the overall risk for abruption decreased over the course of the study, previous cesarean delivery became a stronger contributor for placental abruption.

Conclusion: In our study, a change over time in the specific contribution of different risk factors for placental abruption has been demonstrated.

Key words: Placental abruption, Risk factors, Time trend analysis, Incidence. 


\section{$\underline{\text { Introduction }}$}

Placental abruption is classically defined as partial or complete separation of implanted placenta from the uterine wall before delivery of the baby. It occurs in about $0.8-1 \%$ of pregnancies, depending on the population studied and diagnostic criteria with increasing incidence over the years [1-4]. Placental abruption is frequently associated with perinatal morbidity and mortality [5]. Multiple difficulties, such as altering definition and no united universal classification method together with lack of known etiology or predictive markers makes placental abruption a worldwide challenge and still a "big unknown" [3].

Numerous preexisting conditions are associated with placental abruption. At least 50 different risk factors for placental abruption have been reported, such as preterm premature rupture of membranes, gestational hypertension, preeclampsia and previous cesarean delivery [5,6]. Smoking, preeclampsia and history of previous placental abruption were demonstrated as being the strongest risk factors for placental abruption [3]. As with the incidence of placental abruption, the prevalence of some of its risk factors can also be affected by demographical and epidemiological trends.

Recently, a cohort analysis described different trends in the rates of placental abruption between the US and five countries from Europe (Sweden, Denmark, Norway, Spain and Finland). While in the US the abruption rate has been stable since 2000 , in all other countries declining rates were seen. The most dramatic decline was observed in Denmark. Changes in smoking prevalence partially explained the period effect in the US and Sweden [7]. Other studies also demonstrated shifts in specific risk factors for placental abruption such as cesarean delivery rates. In addition, changes in maternal characteristics, such as older maternal age, reduced parity, high pre- pregnancy weight, and increased weight gain during pregnancy may influence placental abruption incidence over time [8].

As placental abruption is often an unpredictable and life-threatening event, knowledge about its risk factors enables to offer monitoring and prevention measures. Understanding the changes in risk factors as well as the changes in their independent contribution to placental abruption in a growing, developing population, could have a significant impact in managing potential risks. Hence, the aim of this study was to evaluate changes in the independent contribution of different risk factor of placental abruption over time. 


\section{Materials and Methods}

\section{$\underline{\text { Setting }}$}

This retrospective study was conducted at the Soroka University Medical Center (SUMC), a tertiary medical center and the only hospital in the southern part of the country, occupies $65 \%$ of the country's territory. SUMC provides medical services for the entire population of the region (approximately 1.22 million people). Therefore, the study was based on non-selective population data. The institutional review board, in accordance with the Helsinki declaration, approved the study (IRB number 0155-19SOR).

\section{Study population}

All singleton pregnancies of women with and without a placental abruption who delivered between the years 1988-2014 at the SUMC were included in the study. Women with multiple pregnancies and offspring with congenital malformations or chromosomal abnormalities were excluded from the analysis.

\section{Data collection methods}

Data was retrieved from the SUMC's perinatal database, which contains information documented directly after delivery by the attending obstetrician. Data includes information on maternal demographics, clinical characteristics and perinatal outcomes. The information is captured from the patient's medical records and coded according to the ICD-9 codes by trained secretaries.

\section{$\underline{\text { Definitions }}$}

Placental abruption was clinically defined as the premature detachment of an implanted placenta from the uterine wall before the delivery of the fetus [1]. The diagnosis was made by the attending staff during delivery. In some of the cases the diagnosis was confirmed by pathological examination. Nevertheless, as abruption is considered a clinical diagnosis, only some cases of acute abruptions demonstrated histologic confirmation. Maternal exposure, with or without placental abruption, as well as all other clinical characteristics were identified using ICD-9 codes, with ICD-9 code 641.2 for placental abruption. Inadequate prenatal care was defined as less than three visits to any prenatal care facility during pregnancy (9). Polyhydramnios was defined as amniotic fluid index of more than $24 \mathrm{~cm}$ [10]. Maternal diabetes was defined as pre-gestational and gestational diabetes mellitus. Hypertensive disorders were 
defined as chronic hypertension, gestational hypertension and preeclampsia. Large for gestational age was defined as birth weight at or above the $90^{\text {th }}$ percentile for gestational age [11].

\section{Statistical analysis}

Statistical analysis was performed with the SPSS package (SPSS, Chicago, IL).

The initial analysis was performed by using descriptive statistics (mean, SD, graphs), followed by advanced analytical statistics using various parametric tests. Continuous variables with normal distribution were presented as mean \pm standard deviation and compared between the study groups using t-test. Continuous variables which are not normally distributed were presented as median with interquartile range and their statistical analysis was performed using the Mann-Whitney test. Categorical variables were presented in counts and percentages and their statistical analysis was performed using Chi-Square or Fisher Exact test when appropriate.

Two different logistic regression models were constructed in order to identify independent risk factors associated with placental abruption at the different time intervals. To identify trends in the individual contribution of each risk factor, the ORs of each independent risk factor was compared between three consecutive eight- year intervals from 1988 to 2014 (T1 - 1988-1996; T2 - 1997-2005; T3 - 2006-2014). The ORs and their $95 \%$ confidence interval (CI) were calculated for each chosen risk factor. A p value of $<0.05$ was considered statistically significant.

\section{Results}

During the study period 295,946 singleton pregnancies met the inclusion criteria of these, $2170(0.73 \%)$ were complicated by placental abruption.

Rates of placental abruption during the follow up period are displayed in Figure 1. Between 1988 and 2000 , the incidence of placental abruption increased from $0.6 \%$ to $1.0 \%$ and then decreased back to $0.5 \%$ in 2014.

Table 1 presents maternal characteristics and perinatal outcomes of women with and without placental abruption. Women with placental abruption were older with higher parity order compared to women in the control group. Rates of previous cesarean delivery ( $20.4 \%$ vs $12.3 \%, 442$ vs 36238 , p<0.001), IVF pregnancy $(5.5 \%$ vs $2.7 \%, 120$ vs $7910, \mathrm{p}=<0.001)$, recurrent pregnancy loss $(8.0 \%$ vs $5.1 \%, 174$ vs $15124, \mathrm{p}<0.001)$ and inadequate prenatal care $(13.2 \%$ vs $9.2 \%, 287$ vs $26898, \mathrm{p}<0.001)$ were higher 
among women with placental abruption compared to women without placental abruption. Accordingly, abruption was associated with higher rates of hypertensive disorders $(13.3 \%$ vs $5.4 \%, 289$ vs 15957 , $\mathrm{p}<0.001)$, polyhydramnios $(6.1 \%$ vs $3.4 \%, 132$ vs $9925, \mathrm{p}<0.001)$ and premature rupture of membranes $(\mathrm{PROM})(10.1 \%$ vs $8.2 \%, 219$ vs $24110, \mathrm{p}=0.001)$. lower rates of large for gestational age neonate $(5.0 \%$ vs $8.9 \%, 108$ vs $26239, \mathrm{p}<0.001)$ were demonstrated among women with placental abruption.

Table 2 presents a logistic regression model, including all variables found to have a statistically significant association with placental abruption in the univariate analysis. In our population maternal age, grandmultiparity, previous cesarean delivery, recurrent pregnancy loss, IVF pregnancy, inadequate prenatal care, hypertensive disorders, polyhydramnios and PROM were demonstrated to be independent risk factors for placental abruption. Delivery of a large for gestational age neonate was noted as a protecting factor for placental abruption. Looking at the different time periods of our study (Table 2), only previous caesarean delivery, IVF pregnancy, hypertensive disorders, polyhydramnios, and inadequate prenatal care were independently associated with placental abruption in all three time periods. Delivery of a large for gestational age neonate was consistently protective factor for abruption in all three time periods.

In order to improve our analysis, we built another logistic regression model (Table 3) for the prediction of placental abruption including only the variables that were found to be significant in the first multivariate analysis in all three-time periods. While previous cesarean delivery became a stronger contributor to the risk for abruption over the course of the study period, the relative contribution of IVF pregnancy and polyhydramnios to the overall risk for abruption decreased. Hypertensive disorders and inadequate prenatal care demonstrated mixed trends over the periods of the study. Radar chart analysis was used to elucidate the trends in the ORs for independent risk factors for abruption along the study period (Figure 2).

Table 4 compares the rates of the independent risk factors for abruption found in the course of the timeperiod in women with abruption. Rates of previous cesarean delivery demonstrated a rising trend while that of polyhydramnios and hypertensive disorders decreased. All other rates of other risk factors did not change significantly along the time intervals. 


\section{$\underline{\text { Discussion }}$}

Our study found increased incidence of placental abruption between 1988 and 2000, rising from $0.6 \%$ in 1988 to a peak of $1.0 \%$ in 2000 . This was followed by a decrease in the incidence to $0.5 \%$ in 2014. In accordance with our study, Ananth and colleagues, found that the rate of placental abruption among singleton births in the United Sates between 1979 and 2001 increased from 0.81\% in 1979-1981 to 1.0\% in 1999-2001[2]. Other studies from the US, Israel, Taiwan and Norway demonstrated similar trends $[2,12]$. A study from Finland showed a decrease in the incidence of placental abruption between the years 1980-2005, from $0.49 \%$ to $0.34 \%$ [13]. Differences in the incidence of placental abruption between studies may be explained by differences in the prevalence of different risk factors or differences in diagnostic criteria.

We have found five significant risk factors for placental abruption that remained consistently significant in the multivariate analyses in all three time-periods. These included previous cesarean delivery, IVF pregnancy, hypertensive disorders in pregnancy, polyhydramnios and inadequate prenatal care. Large for gestational age was found as a protective factor for abruption in all three time periods. While previous cesarean delivery became a stronger contributor to the risk for abruption over the course of the study period, the relative contribution of IVF pregnancy and polyhydramnios to the overall risk for abruption decreased. Hypertensive disorders and inadequate prenatal care demonstrated mixed trends.

Concurrent with our study, the association between placental abruption and prior cesarean delivery has been demonstrated in previous studies $[4,14]$. Cesarean section rates are rising worldwide with reported rates increasing from $11.2 \%$ to $25 \%$ in Europe, from $22.3 \%$ to $32.3 \%$ in North America and from $4.4 \%$ to $19.5 \%$ in Asia, between the years 1999-2014 [14]. Studies suggest that the uterine low segment adjacent scar may lead to impaired placental implantation. This can lead to impaired placental perfusion, resulting in inadequate blood flow to the intervillous space, and to increased risk of abruption. In addition, ligation of uterine vessels at the time of cesarean section may increase the risk of abruption. Therefore, the association between placental abruption and previous cesarean section may be biologically possible [15].

Compatible with other studies [16], our study also found an independent association between placental abruption and IVF pregnancy. Although the specific mechanism of the association is not fully understood it may be explained by differences in placental formation. When the formation of the chorion is 
initiated in vitro, an inherent difference in the nature of the placenta itself may predispose the patient to develop placental associated morbidities during gestation [16]. The use of IVF is increasing worldwide, between 1995-2016 the number of ART procedures performed in the United States has more than tripled [17]. A report from 49 countries for the year 2000 demonstrated an increase of $5.5 \%$ in IVF treatments [18]. Data collected from 14 European countries showed that the pregnancy rates per aspiration and per transfer were higher in 2014 than in $2013,35.8 \%$ versus $34.5 \%$, respectively [19].

In agreement with our study, the association between hypertensive disorders of pregnancy and placental abruption has been well documented in previous studies [3,4,20]. Research on a large Canadian population demonstrated an increased incidence of preeclampsia from 26.4 per 1000 deliveries in 1989 , to 50.6 in 2012 [21]. A study in Norway, between the years 1967 to 2003, shows an increase in the incidence of preeclampsia from $8 \%$ in 1967-1978 to nearly 20\% in 1991-2003 [22]. Uteroplacental under perfusion or ischemia that may be a result of poor placentation in early pregnancy may be a common mechanism that links hypertensive disorders of pregnancy with placental abruption [20].

Another risk factor for placental abruption found in our study was polyhydramnios, which was described in previous studies as a prominent risk factor for placental abruption $[10,12]$. The association between polyhydramnios and placental abruption may be explained mechanically; an acute reduction in the uterine volume and intrauterine pressure, can lead to a disruption of the utero-placental interface and eventually to placental abruption [12].

Inadequate prenatal care was found to be an independent risk factor for placental abruption in the current study, an association that has been recognized in previous studies [23]. While in industrialized countries, more than $95 \%$ of women undergo at least one prenatal consultation during pregnancy, rates of inadequate prenatal care are much higher in developing countries [24]. Indeed, adequate prenatal care has been shown to decrease vulnerabilities to adverse perinatal outcomes and childbirth related death and disabilities [23]. As adequate prenatal care enables to treat pre-existing medical conditions, pregnancy complications associated with placental abruption such as chronic hypertension and pre-eclampsia could be detected early and managed appropriately.

Delivery of an LGA neonate was found to be a protective factor from abruption in all three time periods. Hypertensive disorders, reflecting chronic processes associated with vascular dysfunction and ischemic placental disease, which were found to be in strong association with placental abruption [4], are associate 
with intra uterine growth restriction and delivery of a small-for-gestational age infant [25]. This may explain the protective association that was found between delivery of an LGA neonate and placental abruption.

Our study's main strength is its utilization of a large cohort, enabling exploration of long-term trends in risk factors for placental abruption. Through the study spanned over a long period (more than two decades), we were able to determine the independent risk factors in each separate time-period and to understand the trends of change during the entire span of the study.

However, our study's main limitation is its retrospective design, which suggests association rather than causation. The fact that there is not a uniform diagnostic definition of placental abruption that is widely accepted likely caused a lack of accuracy in the incidence rates of placental abruption. Lack of information regarding other known risk factors for placental abruption such as substance abuse or previous placental abruption, narrow our understanding of the full spectrum of risk factors for abruption. The observed changes might be due to many factors, including changes in registration. In addition, although the study population was 295,946 , placental abruption is a rare complication and therefor the study outcomes can be limited by the relatively small sample size.

In conclusion, in our study we found various independent risk factors for placental abruption. Although several risk factors are known, there is still more to reveal about the strength of the association and the varying trends. In addition, special attention should be given to women with these risk factors in order to prevent this morbid complication. Even though placental abruption is relatively rare, the consequences may be severe and further research regarding its risk factors is required. There may be room in future studies to choose a more specific study or control group. Nevertheless, our data represents populationbased non-selective data which represents the real world more accurately. 


\section{$\underline{\text { Author contribution }}$}

Erga Schur- Manuscript writing. Data collection and management.

Yael Baumfeld MD - Data collection and management.

Reut Rotem MPH - Data collection and management.

ADI Y. Weitraub MD - Project development. Data collection and management. Manuscript editing.

Gali Pariente MD - Project development. Data collection and management. Manuscript editing. 


\section{$\underline{\text { References }}$}

(1) Ananth CV, Lavery JA, Vintzileos AM, Skupski DW, Varner M, Saade G, et al. Severe placental abruption: clinical definition and associations with maternal complications. Am J Obstet Gynecol 2016 Feb;214(2):272.e1-272.e9.

(2) Oyelese Y, Ananth CV. Placental abruption. Obstet Gynecol 2006 Oct;108(4):1005-1016.

(3) Tikkanen M. Placental abruption: epidemiology, risk factors and consequences. Acta Obstet Gynecol Scand 2011 Feb;90(2):140-149.

(4) Pariente G, Wiznitzer A, Sergienko R, Mazor M, Holcberg G, Sheiner E. Placental abruption: critical analysis of risk factors and perinatal outcomes. J Matern Fetal Neonatal Med 2011 May;24(5):698-702.

(5) Downes KL, Shenassa ED, Grantz KL. Neonatal Outcomes Associated With Placental Abruption. Am J Epidemiol 2017 Dec 15;186(12):1319-1328.

(6) Shobeiri F, Masoumi SZ, Jenabi E. The association between maternal smoking and placenta abruption: a meta-analysis. J Matern Fetal Neonatal Med 2017 Aug;30(16):19631967.

(7) Ananth CV, Keyes KM, Hamilton A, Gissler M, Wu C, Liu S, et al. An international contrast of rates of placental abruption: an age-period-cohort analysis. PLoS ONE 2015;10(5):e0125246.

(8) Joseph KS, Young DC, Dodds L, O'Connell CM, Allen VM, Chandra S, et al. Changes in maternal characteristics and obstetric practice and recent increases in primary cesarean delivery. Obstet Gynecol 2003 10;102(4):791-800.

(9) Twizer I, Sheiner E, Hallak M, Mazor M, Katz M, Shoham-Vardi I. Lack of prenatal care in a traditional society. Is it an obstetric hazard? The Journal of reproductive medicine 2001 Jul;46(7):662.

(10) Kim A, Economidis MA, Stohl HE. Placental abruption after amnioreduction for polyhydramnios caused by chorioangioma. BMJ Case Reports 2018 -03-05;2018:bcr-222399.

(11) Nahavandi S, Price S, Sumithran P, Ekinci EI. Exploration of the shared pathophysiological mechanisms of gestational diabetes and large for gestational age offspring. World journal of diabetes 2019 Jun 15,;10(6):333-340.

(12) Hung TH, Hsieh CC, Hsu JJ, Lo LM, Chiu TH, Hsieh TT. Risk factors for placental abruption in an Asian population. Reprod Sci 2007 Jan;14(1):59-65.

(13) TIKKANEN M, RIIHIMÄKI O, GISSLER M, LUUKKAALA T, METSÄRANTA M, ANDERSSON S, et al. Decreasing incidence of placental abruption in Finland during 19802005. Acta Obstetricia et Gynecologica Scandinavica 2012 Sep;91(9):1046-1052.

(14) Klar M, Michels KB. Cesarean section and placental disorders in subsequent pregnancies--a meta-analysis. J Perinat Med 2014 Sep;42(5):571-583.

(15) Tikkanen M, Nuutila M, Hiilesmaa V, Paavonen J, Ylikorkala O. Prepregnancy risk factors for placental abruption. Acta Obstet Gynecol Scand 2006;85(1):40-44. 
(16) Matsuda Y, Hayashi K, Shiozaki A, Kawamichi Y, Satoh S, Saito S. Comparison of risk factors for placental abruption and placenta previa: case-cohort study. J Obstet Gynaecol Res 2011 Jun;37(6):538-546.

(17) Sunderam S, Kissin DM, Zhang Y, Folger SG, Boulet SL, Warner L, et al. Assisted Reproductive Technology Surveillance - United States, 2016. Morbidity and mortality weekly report. Surveillance summaries (Washington, D.C. : 2002) 2019 Apr 26;;68(4):1-23.

(18) Zegers-Hochschild F, M.D, Mansour, Ragaa, M.D., Ph.D, Ishihara, Osamu, M.D., Ph.D, Adamson GD, M.D, de Mouzon, Jacques, M.D., M.P.H, Nygren, Karl G., M.D., Ph.D, et al. International Committee for Monitoring Assisted Reproductive Technology: world report on assisted reproductive technology, 2005. Fertility and Sterility 2014;101(2):366-378.e14.

(19) De Geyter C, Calhaz-Jorge C, Kupka MS, Wyns C, Mocanu E, Motrenko T, et al. ART in Europe, 2014: results generated from European registries by ESHRE. Human Reproduction 2018 Sep 1,;33(9):1586-1601.

(20) Ananth CV, Peltier MR, Kinzler WL, Smulian JC, Vintzileos AM. Chronic hypertension and risk of placental abruption: is the association modified by ischemic placental disease? Am J Obstet Gynecol 2007 Sep;197(3):273.e1-273.e7.

(21) Auger, Nathalie, MD, MSc, FRCPC, Luo, Zhong-Cheng, MD, PhD, Nuyt, Anne Monique, MD, FRCPC, Kaufman JS, PhD, Naimi AI, PhD, Platt RW, PhD, et al. Secular Trends in Preeclampsia Incidence and Outcomes in a Large Canada Database: A Longitudinal Study Over 24 Years. Canadian Journal of Cardiology 2016;32(8):987.e15-987.e23.

(22) Basso O, Rasmussen S, Weinberg CR, Wilcox AJ, Irgens LM, Skjaerven R. Trends in Fetal and Infant Survival Following Preeclampsia. JAMA 2006 Sep 20;;296(11):1357-1362.

(23) Bibi S, Ghaffar S, Pir MA, Yousfani S. Risk factors and clinical outcome of placental abruption: a retrospective analysis. J Pak Med Assoc 2009 Oct;59(10):672-674.

(24) Rosa CQ, Silveira DS, Costa JS. Factors associated with lack of prenatal care in a large municipality. Rev Saude Publica 2014 Dec;48(6):977-984.

(25) Ananth CV, Friedman AM. Ischemic placental disease and risks of perinatal mortality and morbidity and neurodevelopmental outcomes. Semin Perinatol 2014 Apr;38(3):151-158. 


\section{$\underline{\text { Statements and Declarations }}$}

The authors declare that no funds, grants, or other support were received during the preparation of this manuscript. The authors have no relevant financial or non-financial interests to disclose. 
Figure 1- Incidence of placental abruption along the study period 
Table 1 - Incidence of risk factors for placental abruption

\begin{tabular}{|c|c|c|c|}
\hline Variables & $\begin{array}{c}\text { Placental } \\
\text { abruption } \\
(\mathrm{n}=2,170) \\
\mathrm{n}(\%)\end{array}$ & $\begin{array}{c}\text { No placental } \\
\text { abruption } \\
(\mathrm{n}=293776) \\
\mathrm{n}(\%)\end{array}$ & $\mathrm{P}$ value \\
\hline $\begin{array}{l}\text { Maternal age, years, (mean } \\
+ \text { +SD) }\end{array}$ & $29.79 \pm 6.22$ & $28.64 \pm 5.84$ & $<0.001$ \\
\hline Grandmultiparity & $610(28.1)$ & $63282(21.5)$ & $<0.001$ \\
\hline Recurrent pregnancy loss & $174(8.0)$ & $15124(5.1)$ & $<0.001$ \\
\hline Previous cesarean delivery & $442(20.4)$ & $36238(12.3)$ & $<0.001$ \\
\hline IVF pregnancy & $120(5.5)$ & $7910(2.7)$ & $<0.001$ \\
\hline Inadequate prenatal care & $287(13.2)$ & $26898(9.2)$ & $<0.001$ \\
\hline $\begin{array}{l}\text { Hypertensive disorders in } \\
\text { pregnancy }\end{array}$ & $289(13.3)$ & $15957(5.4)$ & $<0.001$ \\
\hline Maternal diabetes mellitus & $131(6.0)$ & $16201(5.5)$ & 0.29 \\
\hline Polyhydramnios & $132(6.1)$ & 9925 (3.4) & $<0.001$ \\
\hline Premature rupture of membranes & $219(10.1)$ & $24110(8.2)$ & 0.001 \\
\hline $\begin{array}{c}\text { Gestational age, weeks, (mean + } \\
\text { SD) }\end{array}$ & $34.20 \pm 5.15$ & $38.91 \pm 2.37$ & $<0.001$ \\
\hline Large for gestational age & $108(5.0)$ & $26239(8.9)$ & $<0.001$ \\
\hline
\end{tabular}


Table 2 - Multivariable logistic regression models for placental abruption in three time periods including all significant risk factors in univariate analysis.

Goodness of fit- model A:

\begin{tabular}{|c|c|c|c|c|}
\hline Variables & All & $\leq 1997$ & $1998-2005$ & $\geq 2006$ \\
\hline Omnibus test & $<0.001$ & $<0.001$ & $<0.001$ & $<0.001$ \\
\hline -2LL & 204037.19 & 7810.65 & 9247.67 & 6891.67 \\
\hline $\begin{array}{c}\text { Hosmer and } \\
\text { Lemeshow }\end{array}$ & 0.23 & 0.97 & 0.03 & 0.11 \\
\hline
\end{tabular}

\begin{tabular}{|c|c|c|c|c|}
\hline Variables & $\begin{array}{c}\text { All } \\
\text { OR (95\% CI, p } \\
\text { value })\end{array}$ & $\begin{array}{c}\leq 1997 \\
\text { OR }(95 \% \mathrm{CI}, \mathrm{p} \\
\text { value) } \\
\mathrm{N}=97406\end{array}$ & $\begin{array}{c}1998-2005 \\
\text { OR (95\% CI, p } \\
\text { value) } \\
\mathrm{N}=100726\end{array}$ & $\begin{array}{c}\geq 2006 \\
\text { OR (95\% } \\
\text { CI, } p \text { value) } \\
\mathrm{N}=99009\end{array}$ \\
\hline Maternal age & $\begin{array}{l}1.01(1.01- \\
1.02,0.001)\end{array}$ & $\begin{array}{c}1.01(1.00-1.03, \\
0.03)\end{array}$ & $\begin{array}{c}1.02(1.01-1.03, \\
0.01)\end{array}$ & $\begin{array}{l}1.01(0.99- \\
1.03,0.29)\end{array}$ \\
\hline Grandmultiparity & $\begin{array}{c}1.26(1.13-1.41, \\
<0.001)\end{array}$ & $\begin{array}{c}1.27(1.03-1.57, \\
0.03)\end{array}$ & $\begin{array}{l}1.05(0.88- \\
1.25,0.57)\end{array}$ & $\begin{array}{c}1.55(1.27- \\
1.90 \\
<0.001)\end{array}$ \\
\hline $\begin{array}{c}\text { Previous cesarean } \\
\text { delivery }\end{array}$ & $\begin{array}{c}1.70(1.52-1.90, \\
<0.001)\end{array}$ & $\begin{array}{c}1.49(1.20-1.85, \\
<0.001)\end{array}$ & $\begin{array}{c}1.80(1.52-2.13, \\
<0.001)\end{array}$ & $\begin{array}{c}1.84(1.51- \\
2.23 \\
<0.001)\end{array}$ \\
\hline $\begin{array}{c}\text { Recurrent } \\
\text { pregnancy loss }\end{array}$ & $\begin{array}{c}1.44(1.23- \\
1.69<0.001)\end{array}$ & $\begin{array}{c}1.47(1.09-1.97, \\
0.01)\end{array}$ & $\begin{array}{c}1.40(1.09-1.79, \\
0.01)\end{array}$ & $\begin{array}{l}1.44(1.08- \\
1.94,0.14) \\
\end{array}$ \\
\hline IVF pre & $\begin{array}{c}2.03(1.67-2.46, \\
<0.001)\end{array}$ & $\begin{array}{c}2.61(1.86-3.67, \\
<0.001)\end{array}$ & $\begin{array}{c}1.96(1.44-2.67< \\
0.001)\end{array}$ & $\begin{array}{l}1.79(1.24- \\
2.60,0.01)\end{array}$ \\
\hline $\begin{array}{l}\text { Hypertensive } \\
\text { disorders }\end{array}$ & $\begin{array}{c}2.50(2.20-2.85, \\
<0.001)\end{array}$ & $\begin{array}{c}2.45(1.97-3.05, \\
<0.001)\end{array}$ & $\begin{array}{c}2.65(2.18-3.22, \\
<0.001)\end{array}$ & $\begin{array}{c}2.09(1.57- \\
2.78 \\
<0.001) \\
\end{array}$ \\
\hline Polyhydramnios & $\begin{array}{c}1.89(1.57-2.26, \\
<0.001)\end{array}$ & $\begin{array}{c}2.04(1.56-2.67, \\
<0.001)\end{array}$ & $\begin{array}{c}1.73(1.26-2.38, \\
0.001)\end{array}$ & $\begin{array}{l}1.75(1.16- \\
2.62,0.01)\end{array}$ \\
\hline $\begin{array}{l}\text { Premature rupture } \\
\text { of membranes }\end{array}$ & $\begin{array}{c}1.32(1.14-1.52, \\
<0.001)\end{array}$ & $\begin{array}{c}1.99(1.52-2.61, \\
<0.001)\end{array}$ & $\begin{array}{c}1.09(0.85-1.39, \\
0.50)\end{array}$ & $\begin{array}{l}1.33(1.05- \\
1.69,0.02)\end{array}$ \\
\hline $\begin{array}{l}\text { Inadequate } \\
\text { prenatal care }\end{array}$ & $\begin{array}{c}1.63(1.43-1.87, \\
<0.001)\end{array}$ & $\begin{array}{c}1.64(1.30-2.05, \\
<0.001)\end{array}$ & $\begin{array}{c}1.79(1.42-2.26, \\
<0.001)\end{array}$ & $\begin{array}{c}1.57(1.22- \\
2.03,0.001)\end{array}$ \\
\hline $\begin{array}{c}\text { Large for } \\
\text { gestational age }\end{array}$ & $\begin{array}{c}0.47(0.38-0.57, \\
<0.001)\end{array}$ & $\begin{array}{c}0.44(0.29-0.60 \\
<0.001)\end{array}$ & $\begin{array}{c}0.41(0.30-0.55, \\
<0.001)\end{array}$ & $\begin{array}{l}0.62(0.42- \\
0.92,0.02)\end{array}$ \\
\hline
\end{tabular}


Table 3 - Multivariable logistic regression models for placental abruption in three time periods including all significant risk factors in the multivariate analysis for all three time periods.

Goodness of fit- model B:

\begin{tabular}{|c|c|c|c|c|}
\hline Variables & All & $\leq 1997$ & $1998-2005$ & $\geq 2006$ \\
\hline Omnibus test & $<0.001$ & $<0.001$ & $<0.001$ & $<0.001$ \\
\hline -2LL & 25174.10 & 8039.09 & 9776.03 & 7290.54 \\
\hline $\begin{array}{c}\text { Hosmer and } \\
\text { Lemeshow }\end{array}$ & 0.18 & 0.18 & 0.79 & 0.28 \\
\hline
\end{tabular}

\begin{tabular}{|c|c|c|c|c|}
\hline Variables & $\begin{array}{l}\text { All } \\
\text { OR ( } 95 \% \mathrm{CI}, \mathrm{p} \\
\text { value) }\end{array}$ & $\begin{array}{l}\leq 1997 \\
\text { OR (95\% CI, p } \\
\text { value) } \\
\mathrm{N}=97406\end{array}$ & $\begin{array}{l}1998-2005 \\
\text { OR }(95 \% \mathrm{CI}, \mathrm{p} \\
\text { value) } \\
\mathrm{N}=100726\end{array}$ & $\begin{array}{l}\geq 2006 \\
\text { OR ( } 95 \% \text { CI, p } \\
\text { value) } \\
\mathrm{N}=99009\end{array}$ \\
\hline $\begin{array}{l}\text { Previous } \\
\text { cesarean delivery }\end{array}$ & $\begin{array}{l}1.81(1.63- \\
2.01,<0.001)\end{array}$ & $\begin{array}{l}1.59(1.29-1.97, \\
<0.001)\end{array}$ & $\begin{array}{l}1.90(1.61-2.24,< \\
0.001)\end{array}$ & $\begin{array}{l}1.97(1.64-2.37, \\
<0.001)\end{array}$ \\
\hline IVF pregnancy & $\begin{array}{l}2.01(1.67- \\
2.42,<0.001)\end{array}$ & $\begin{array}{l}2.56(1.83-3.58, \\
<0.001)\end{array}$ & $\begin{array}{l}2.11(1.57-2.82, \\
<0.001)\end{array}$ & $\begin{array}{l}1.58(1.10-2.27, \\
0.01\end{array}$ \\
\hline $\begin{array}{l}\text { Hypertensive } \\
\text { disorders in } \\
\text { pregnancy }\end{array}$ & $\begin{array}{l}2.59(2.28- \\
2.94,<0.001)\end{array}$ & $\begin{array}{l}2.50(2.01-2.10, \\
<0.001)\end{array}$ & $\begin{array}{l}2.85(2.36-3.43 \\
<0.001)\end{array}$ & $\begin{array}{l}2.11(1.60-2.79, \\
<0.001)\end{array}$ \\
\hline Polyhydramnios & $\begin{array}{l}1.95(1.63- \\
2.33,<0.001)\end{array}$ & $\begin{array}{l}2.08(1.59-2.72, \\
<0.001)\end{array}$ & $\begin{array}{l}1.88(1.38-2.54, \\
<0.001)\end{array}$ & $\begin{array}{l}1.83(1.23-2.72, \\
0.01)\end{array}$ \\
\hline $\begin{array}{l}\text { Inadequate } \\
\text { prenatal care }\end{array}$ & $\begin{array}{l}1.67(1.47- \\
1.90,<0.001)\end{array}$ & $\begin{array}{l}1.67(1.34-2.05, \\
<0.001\end{array}$ & $\begin{array}{l}1.76(1.43-2.17, \\
<0.001)\end{array}$ & $\begin{array}{l}1.66(1.31-2.10, \\
<0.001)\end{array}$ \\
\hline $\begin{array}{l}\text { Large for } \\
\text { gestational age }\end{array}$ & $\begin{array}{l}0.50(0.41- \\
0.61,<0.001)\end{array}$ & $\begin{array}{l}0.45(0.32-0.64, \\
<0.001)\end{array}$ & $\begin{array}{l}0.43(0.32-0.57, \\
<0.001)\end{array}$ & $\begin{array}{l}0.67(0.46-0.99, \\
0.04)\end{array}$ \\
\hline
\end{tabular}


Figure 2 - Trends in the ORs for independent risk and protective factors for abruption along the study period. 
Table 4 - Comparison of rates of risk factors for placental abruption found along the time period.

\begin{tabular}{|c|c|c|c|c|}
\hline Variables & $\begin{array}{c}\leq 1997 \\
\mathrm{n}(\%)\end{array}$ & $\begin{array}{c}1998-2005 \\
\mathrm{n}(\%)\end{array}$ & $\begin{array}{c}\geq 2006 \\
\mathrm{n}(\%)\end{array}$ & P value \\
\hline $\begin{array}{c}\text { Previous cesarean } \\
\text { delivery }\end{array}$ & $102(14.8)$ & $185(21.2)$ & $155(25.5)$ & $<0.001$ \\
\hline IVF pregnancy & $38(5.5)$ & $50(5.7)$ & $32(5.3)$ & 0.93 \\
\hline $\begin{array}{c}\text { Hypertensive } \\
\text { disorders in } \\
\text { pregnancy }\end{array}$ & $98(14.2)$ & $135(15.5)$ & $56(9.2)$ & 0.01 \\
\hline Polyhydramnios & $61(8.8)$ & $45(5.2)$ & $26(4.3)$ & 0.001 \\
\hline $\begin{array}{c}\text { Inadequate prenatal } \\
\text { care }\end{array}$ & $101(14.6)$ & $104(11.9)$ & $82(13.5)$ & 0.28 \\
\hline
\end{tabular}


Figures

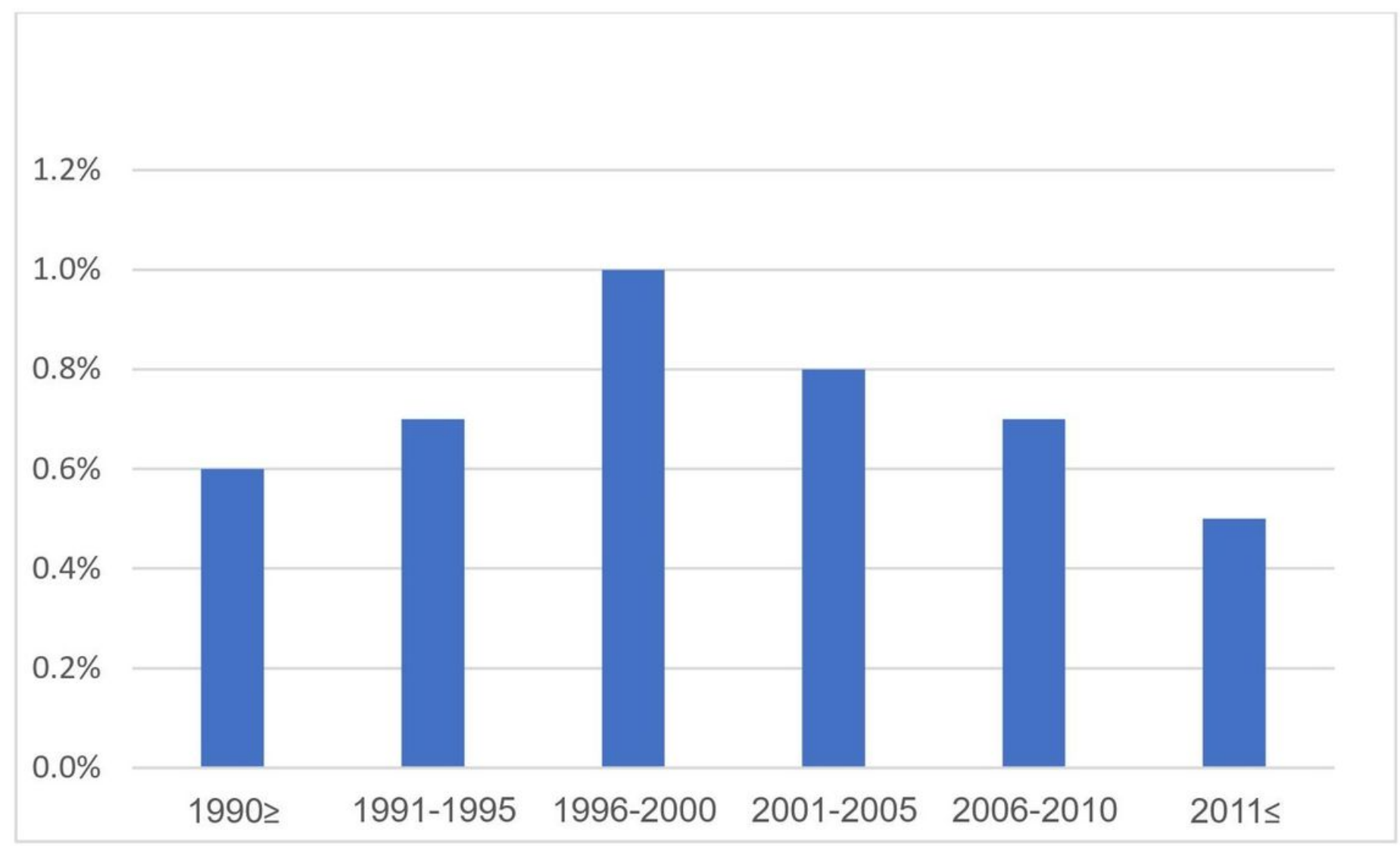

\section{Figure 1}

Incidence of placental abruption along the study period 


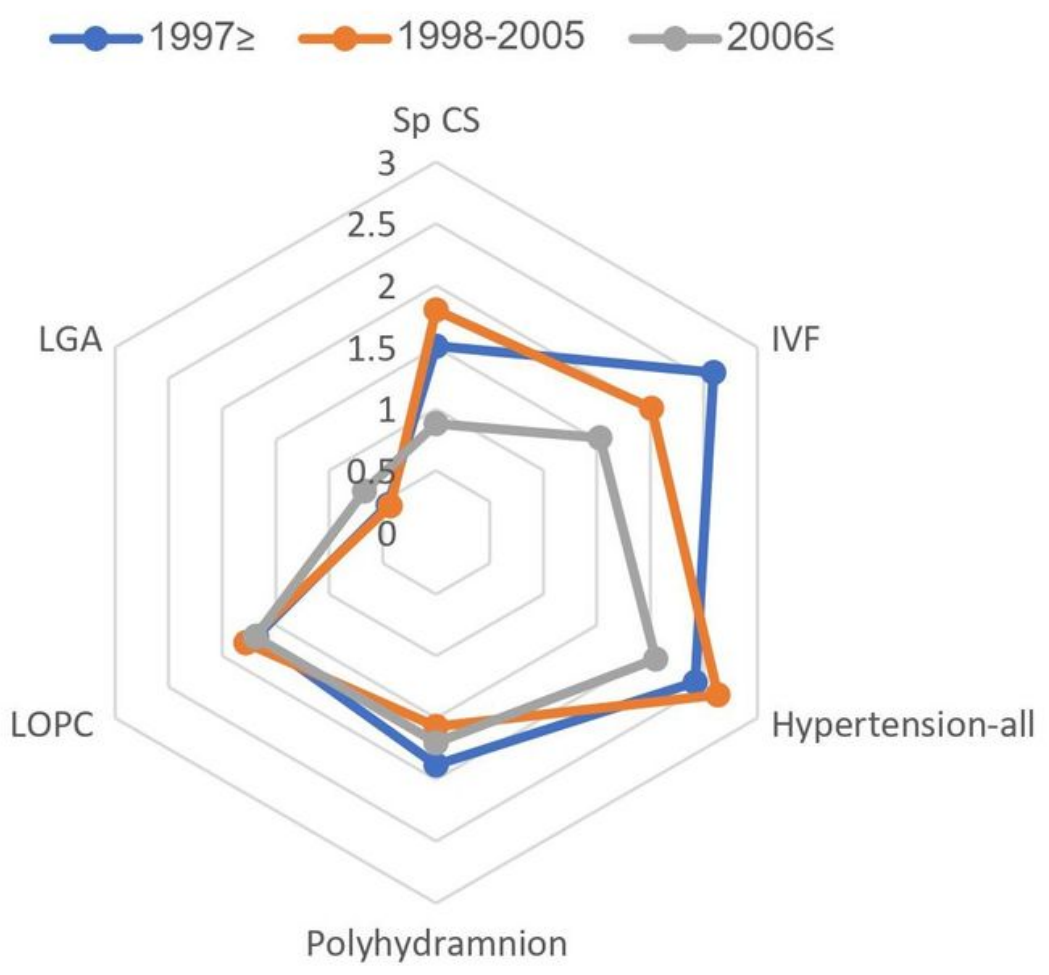

\section{Figure 2}

Trends in the ORs for independent risk and protective factors for abruption along the study period. 